\title{
CIENCIAS NO DIVINAS: CIENCIA Y CULTURA EN EL HELENISMO
}

\author{
NON-DIVINE SCIENCES: SCIENCE AND \\ CULTURE IN HELLENISM
}

\author{
ELOY RADA GARCíA ${ }^{1}$
}

Facultad de Filosofía

UNED

Resumen: La evolución de la cultura humana es un largo proceso cuya explicación han intentado los historiadores desde los más diversos puntos de vista. La complejidad del desarrollo y sucesión de las culturas exige comprender por igual lo que surge como novedad y lo que permanece, explícito o implícito, en las sucesivas formas culturales. La Historia heroica (de los hechos gloriosos o catastróficos) no basta para ello. Otra forma de ver el continuo socio-cultural (darwiniano o cuasidarwiniano, en clara analogía con el biológico) permite comprender el proceso en términos de "descendencia con variación" de "supervivencia del mejor adaptado", etc., siempre que estas categorías explicativas se entiendan también analógicamente en su contexto cultural-antropológico. Se ha repetido innumerables veces que nuestra cultura es de origen griego y se habla de la "herencia clásica", como si de una dote conocida y compartida se tratase. Aquí pretendo mostrar, primero y esquemáticamente, la complejidad cultural acumulada en la cultura historiográfica helenística y, después, señalar algunos factores, tanto griegos como exógenos, incorporados a ese legado y trasmitidos en él hasta nuestros días. La consideración memética, aquí

\footnotetext{
${ }^{1}$ Profesor Emérito de la Facultad de Filosofía de la UNED; Dpto. de Lógica, Historia y Filosofía de la Ciencia. E-mail: caprilander@gmail.com
} 
implícita, de todos estos factores permite una interpretación naturalista de la evolución cultural que ha llegado hasta el presente. Puede ser relevante que, además de los entramados sociales, entre esos factores se hallen principalmente la ciencia, las técnicas o los cultos sociales junto con las concepciones filosóficas o religiosas. Sin embargo, la mayor relevancia reside, tal vez, en la posibilidad metodológica de comprender más radicalmente los procesos culturales en términos naturalizados. Tomamos al Helenismo como ensayo.

Palabras Clave: Helenismo, religión, cultura, tecnología, naturalismo.

Aвstract: Here I intend to show, first and schematically, the cultural complexity accumulated in Hellenistic historiographical culture and then will I point out some factors, both Greeks and exogenous factors, which they have been incorporated and transmitted to this day. The consideration of memetics, implied here, of all these factors allows a naturalistic interpretation of the cultural evolution that has reached the present.

KeYwords: Hellenism, culture, religion, technology, naturalism.

\section{Introducción}

Todo regreso al pasado es siempre una ficción que podemos condimentar con estrategias literarias más o menos sofisticadas, según el gusto. La metodología científica que nos exige la ciencia histórica es lo suficientemente variada como para permitirnos diferentes representaciones aceptables para el gusto de cada época, e incluso para el gusto de cada espectador. Hay, sin embargo, dos grandes bloques de panorámicas en las reconstrucciones históricas. Un primer bloque de historias se basa en presentar cuadros en los que aparecen los grandes eventos distintivos que consideramos relevantes y que permiten escribir nuestro discurso con puntos y aparte. En este género de historias nuestro ficcional discurso, que calificaríamos de saltacionista, va dando saltos de tiempo en tiempo o de evento en evento, acotando a uno como primero o inicial y a otro como último o final. Típicamente es el caso de autores que acotan el período helenístico entre el año 323, a.c, (muerte de Alejandro) y el año 30-31, a.c (batalla de Actium en que Octavio derrota a Marco Antonio y Cleopatra) y convierte a Egipto en Provincia romana. Y, entre uno y otro, las hazañas de este o aquel Diadoco, ya sean Átalos o Pirros, Seleucos o Ptolomeos, por no mencionar a otros protagonistas. En este modelo la historia resulta de la sucesión de elementos discretos que son 
entendidos como causas o marcas más o menos determinantes de las transformaciones sociales, políticas o culturales registradas como épocas, períodos o eras. El énfasis estará, por tanto, en los eventos nuevos que pueden registrarse como causas del cambio histórico para cada momento dado en la sucesión temporal de la humanidad. En este modelo de historias es inevitable la presencia de los grandes protagonistas como causantes de grandes transformaciones.

El otro modelo de historias, que podríamos denominar gradual, trata de contemplar la corriente de la historia como un continuo fluir de sucesos encadenados, no solo por el lento y continuo acontecer en el tiempo, sino también por la interna e inevitable coincidencia de diferentes actores y distintas circunstancias ambientales cuya concurrencia produce variaciones solo perceptibles a largo plazo sobre un fondo humano, social y cultural común. Constantemente algo cambia y mucho permanece y de ambas cosas trata de dar cuenta este modelo de historia cuyo mayor protagonista es la sociedad entera y, con ella, la cultura en y con la que vive. El gradualismo procura dar cuenta de la dinámica interna de los factores que intervienen en los cambios continuos, siempre en el supuesto de que el cambio y la permanencia se producen dentro de los límites de la necesidad de supervivencia de la humanidad. Si tomamos con las debidas cautelas la noción de meme, propuesta por R. Dawkins, como sujeto de la evolución cultural y aceptamos que aquí el término designa a bloques mayores o menores de la cultura helenística que sufren variaciones a lo largo del tiempo, pero permanecen fenotípicamente transformados en el seno de la misma, quizá pudiéramos disponer de un modelo teórico aplicable a la imagen que pretendemos exponer. Por eso, en esta perspectiva, es igualmente importante el estudio de los factores del cambio y el de las causas y formas de permanencia y, por tanto, se necesita identificar a unos y otras en el entramado social, político, económico, cultural y antropológico de cada momento estelar (convencionalmente elegido para el caso).

Aquí, a modo de ensayo, propondremos algunos de esos factores que, en nuestra opinión, contribuyen a interpretar los dos aspectos de permanencia y cambio en el helenismo. Cambio o transformación de la herencia clásica y permanencia bajo formas nuevas de lo que resultó de aquellas transformaciones. La idea final resultante sería que aún hoy estamos dentro del marco creado en y a partir del helenismo, cuyas fórmulas políticas, religiosas, sociales y científico-culturales nos rodean universalmente. Para el lector dejamos la tarea de reconocer o identificar en ellas las múltiples variantes del presente. 


\section{Historia o historias. Una ciencia que nace y crece}

No es empresa fácil para los historiadores, pese al caudal de textos y fragmentos supervivientes, abordar la literatura histórica de la época alejandrina. Tras la estela de Herodoto y Tucídides, apenas si encontramos en los siglos inmediatos a la muerte de Alejandro seguidores de los modelos de historein que ellos iniciaron y que, en cierto modo, constituyeron el patrón al que vino a ajustarse la ciencia histórica. Aparentemente los historiadores helenísticos siguen en la tradición de Tucídides, contando las historias de las ciudades-estado y sus conflictos, pero cada vez más distantes de la posición crítica de Tucídides. Proliferan entonces las cronologías (Hipias de Elis nos había legado un siglo antes la de los ganadores de las Olimpiadas desde su inicio en 776 a.c), las genealogías o, más comúnmente, las narraciones de hechos, a veces interconectados, que se encadenan a través de las relaciones entre ciudades-estado, o entre protagonistas - tiranos o reyes- de acontecimientos más o menos extraordinarios. Estas series de crónicas localistas son conocidas con el nombre de hellenica, muchas de ellas perdidas ya en época romana.

Una de estas fue la serie hellenica de Teopompo de Quíos (380-323 a. c.), que era una pretendida continuación de la Historia de Tucídides (desde 411 a 395 a.c.) y, sobre todo, su obra más importante (58 libros), Las Filipicas, dedicadas a la vida y hechos de Filipo II de Macedonia, desde su ascenso al trono en 359 hasta su muerte en 336 a.c. Aquí Teopompo inicia un género de historia que podríamos llamar historia-denuncia, pues se adentra en los entresijos de las corrupciones permanentes en Atenas y otros lugares y se deleita contando los vicios y crueldades de Filipo el nuevo Rey de todos los griegos.

Contemporáneo suyo fue Éforo de Cyma (380-330 a.c.) con una serie de 30 libros en la que pretende, por una parte, deslindar la historia del mito abarcando todo el periplo griego desde los hijos de Heracles hasta el año 341 a.c., aunque, por otra parte, introduce en la historia su propia vena imaginativa con el fin de "maravillar" o, al menos, convencer al lector más que indagar la verdad. Su Isocrática ascendencia retórica le lleva a presentar los hechos en términos "convincentes" y produce con ello un efecto perverso en su relato; lo convierte en lo que hoy llamamos "novela histórica" o, en otro sentido, "historia-magistra".

Dos cosas podemos destacar a este propósito: La primera, que a la muerte de Alejandro los historiadores estaban ya practicando estos dos géneros de 
historia, biográfica una y ejemplarizante la otra. La segunda tiene que ver con la introducción en el campo de estudio de los historiadores un inmenso territorio "alejandrino" desde el Bósforo al Indo y desde Afganistán a Sudán y con ello, la irrupción de nuevos mitos y culturas, además de ciudades y religiones, en el ámbito cultural heleno.

La figura divinizada de Alejandro y después la presencia de y culto a los Reyes en los distintos reinos surgidos tras su muerte, propició materia biográfica, pero también mítica, para la proliferación de "historias", míticas o anecdóticas la mayor parte, que incorporaban personajes de todas clases, culturas o cultos y religiones. La primera "historia" de Alejandro se debió a Calístenes, sobrino de Aristóteles, elegido por el propio Alejandro como cronista y testigo de los hechos de su marcha a Oriente. Su historia devino un cúmulo de adulaciones y un rosario de quejas, hasta que en 327 a.c. acabó ejecutado y hoy disponemos de un conjunto de escritos de escaso o nulo rigor histórico editados bajo la rúbrica de Pseudo-Calistenes por la incertidumbre que hay sobre sus autores. Pero además Alejandro contó con una plana de cronistas presenciales de la campaña asiática y sin embargo la biografía canónica que poseemos es muy posterior, es la del historiador greco-romano Lucio Flavio Arriano (86-175 d.c.) sobre la base de textos aparentemente fiables de Aristóbulo, Ptolomeo y Nearco, que acompańaron a Alejandro en su larga expedición. Pero los hechos atribuidos a Alejandro por los "historiadores" de esa época inmediatamente posterior a su muerte son más bien materia de leyenda que de historia y cuya mejor síntesis podría ser la obra de Quinto Curtio Rufo. En su conjunto son la base del Poema de Alexandre, de larga tradición medieval en la literatura occidental.

Una segunda elaboración también tardía, es la Biblioteca Histórica de Diodoro Sículo en 40 libros que incorpora resúmenes de los datos procedentes de la mayor parte de las obras de los autores aún disponibles en su tiempo (70 al 30 a.c.), tales como Hecateo de Abdera, Timeo, Posidonio, Jerónimo de Cardia, Éforo, Ctesias, Duris de Samos, Teopompo, Polibio, Diylus, etc. Merecen especial mención, como ejemplos de su presencia en Diodoro, Jerónimo de Cardia, que murió el año 260 a.c. - a la edad de 104 años y cuya obra aparece en la base de Diodoro para los libros 18-20 que nos dan noticia muy detallada de las guerras entre los sucesores de Alejandro hasta el establecimiento de los grandes reinos alejandrinos, o Hecateo de Abdera, amigo personal de Ptolomeo I y cuya obra sobre la historia egipcia está en la base del libro I de Diodoro. Hecateo escribe para Ptolomeo e introduce de nuevo al servicio del reino egipcio el modelo de historia de la ciudad-estado, aunque ahora sea reino y no mera Polis egemónica. 
Le seguirá en esta tarea un sacerdote egipcio, Manetho, a quien debemos la cronología que aún hoy es la base de la historia egipcia.

Y algo parecido ocurre con el reino seléucida, donde Berosso, un sacerdote bilingüe de Baal, escribió una historia de Babilonia en griego y Megastenes, embajador de Seleuco ante el emperador Sendragupta de la India escribió una admirable historia de la fundación del imperio de Mauryan (320-185 a.c.).Aunque sean historias parciales o locales, estas muestras nos ilustran sobre la ampliación tanto geográfica como etnográfica y cultural que experimenta la historia como consecuencia de las conquistas de Alejandro.

Otro ejemplo de Historia Universal que podríamos destacar sería la extensa obra de Polibio (200-118 a.c.) Historia General en 40 libros que, en realidad, son una historia de la expansión y conquista romana del mundo mediterráneo hasta su consolidación como imperio a finales del siglo $2^{\circ}$ a.c. Si repasamos la obra de Polibio, pese a su implicación personal en la política de independencia de la Liga Aquea frente a Roma, tampoco sale de la categoría localista (Roma como protagonista) de la Ciudad-Estado, aunque la expansión de Roma ya desbordase geográficamente ese tipo de realidad política. Y, de paso, nos sirve ahora para constatar que la tradición historiográfica griega, tras múltiples variaciones, se nos trasmite justo a través de los propios griegos que escriben la historia de Roma y, mediante esta, nos llega a nosotros de la mano de enciclopedistas tales como el propio Polibio, Dionisio de Halicarnaso, Diodoro Sículo, etc.

Pero no deberíamos olvidar tras este breve repaso que, desde Herodoto y Tucídides al menos, existe una tradición metodológica a la hora de hacer historia (historein significa originariamente investigar una cosa) y por ello se ha asumido que la primera declaración explícita de historia como investigación es de Herodoto ya el comienzo mismo de las historiai:

Esta es la narración de las investigaciones de Herodoto de Halicarnaso, emprendida con el fin de que las hazañas de los hombres no sean olvidadas con el paso del tiempo y las grandes y admirables obras de los griegos y de los bárbaros no carezcan de fama y no se olvide la razón por la que lucharon unos con otros. 
Y, puesto que la tradición historiográfica griega es también nuestra tradición, debemos ahora distinguir cuidadosamente, en el contexto del legado literario helenístico, los textos que responden a la exigencia metodológica de investigación que establecía la tradición ya en aquel momento, respecto de aquellos otros que desconocieron o alteraron por cualquier motivo dicha exigencia y, por mucho valor literario que encierren, tendríamos que clasificarlos entre los escritos parahistóricos, es decir, ensayos y variaciones en torno a momentos históricos o a estilos de hacer historia que, pese a todo, a la larga han dejado una secuela aún viva en nuestros días. Euhémero en la corte de Casandro en Macedonia, Calímaco y Apolonio en la corte de Alejandría, son ejemplos de la deriva en que entran los centros de cultura literaria vinculados a los reyes alejandrinos. Es cierto que Euhémero (p.e.) introduce una variante escéptica en la interpretación de los mitos griegos y "racionaliza" en términos antropológicos o meramente naturalistas tanto a los dioses (Zeus era un rey de Creta divinizado por sus súbditos y su tumba estaba cerca del palacio de Knosos) como a las historias de sus hazañas que reduce a fenómenos naturales o eventos ritualizados. Esta forma de racionalidad antropológica, que también se puede encontrar en Éforo y otros, permitió, de paso, trasladar los hechos históricos y sus protagonistas a un lenguaje mítico sin, por ello, provocar sorpresa o crítica, ya que, si una vez los dioses fueron hombres, nada impedía que los hombres llegaran de nuevo a ser dioses.

Quizá, para cerrar esta breve presentación del nacimiento de la historia como ciencia, sea mejor hacerlo con las palabras de Oswin Murray:

Durante 350 años la tradición griega de escribir historia inventó la mayor parte de los estilos de historia que todavía practicamos, y que trata de analizar muchos de los problemas políticos y sociales que aún encaramos. Esta tradición ha establecido estándares de exactitud y variedad de enfoques que la hacen claramente superior a cualquier otra tradición histórica. Si tiene un defecto, se trata de un defecto que compartimos, la incapacidad de manejarnos con el poder de Dios en historia, feliz la edad que puede permitirse ignorar a Dios. El final del período helenístico conoció los inicios de una nueva religión, y el fluir conjunto de las tradiciones de Grecia y de Judea hacia una nueva forma de historia, la irrupción de la salvación de Dios en la tierra. Los Libros de los Macabeos y las obras de Josefo son producto de esta fusión de 
tradiciones culturales que sobrevive, mostrando el camino a seguir hacia la Historia de la Iglesia de Eusebio y del mundo cristiano de Bizancio. ${ }^{2}$

Quizá O. Murray no se percatase aquí de un hecho trascendental. Además de "una nueva religión" (el cristianismo) el final del helenismo dejó otras dos, aún hoy vivas: El judaísmo, ya entonces muy helenizado y diasporizado, y en el horizonte inmediato el islam enlazado con la tradición helenística de las Revelaciones Apocalípticas y cuya proyección en la historia no es menor que la de las otras dos. Otra observación no menos relevante sería que "la salvación de Dios", para los creyentes, ya hacía siglos que estaba en la oferta de las divinidades de los cultos mistéricos, como veremos. La idea de "la salvación de Dios en la tierra" (sotería en griego) incluía la felicidad en esta vida y en la otra. Es una especie de garantía universal contra la desgracia, contra el dolor y contra la muerte. Bajo fórmulas ligeramente distintas la encontramos presente en las Escuelas socráticas y como idea-ambiente en todos los círculos filosóficos derivados del platonismo, sobre todo. La idea de alma-inmortal o de "otra vida eterna" no era una idea de origen bíblico y por ello cabe atribuir al helenismo la presencia de esta en la cultura posterior.

\section{Fusión de culturas. Cambio y permanencia invisibles}

En el año 260 a.c.- el rey indio Asoka, recién convertido al budismo promulgó un edicto para ser publicado mediante inscripciones en todo su imperio de Mauriya (casi toda la actual India y Pakistan) y destinado a "sus niños del mundo". Menciona con exactitud a todos los reyes helenísticos desde su misma frontera hasta Macedonia, Cirene o Egipto. Este edicto estaba escrito en prakrit por todo el imperio, pero en el noroeste también en arameo y en griego; una copia en este idioma se conserva inscrita en su piedra original en Kandahar (Afganistán) en el lugar donde estaba el asentamiento macedonio, invitando a todos a llevar vidas de tolerancia y auto-sacrificio.

${ }^{2}$ Cfr. Boardman, John Griffin J. y Murray, O. (eds.); en: Greece and the Hellenistic World. Oxford (1989), "Greek Historians" p. 195. 
Aunque las relaciones más intensas con la India fueron protagonizadas por los Seléucidas, este dato nos muestra que hubo una corriente de transferencias mutuas cuyos contenidos no siempre podemos identificar. Elementos de la cultura griega debieron llegar hasta la India, pues en Ai- Khanoum -segunda ciudad de Afganistán- se ha descubierto y excavado un Gymnasium del s.II a.c. con los típicos espacios comunes para la enseñanza y la discusión, lo que prueba que, no solo llegó hasta aquellas remotas regiones del Noreste el idioma, sino que además existió una política de instrucción de la juventud en los términos de la idea helenizante de Alejandro.

Por lo que sabemos en todos los reinos se construyeron y dotaron bibliotecas. Aunque las más famosas sean las de Alejandría y Pérgamo, hay que conceder que tanto en sus recintos como en el entorno de cada una de ellas existió un grupo de sabios y eruditos griegos y también nativos con acceso a textos de muy variada índole. Hoy aún disponemos de muchos textos, incluso científicos, gracias a que previamente fueron vertidos del griego al siríaco o al copto y circularon en estos idiomas durante siglos ya desde bastante antes de la Era. Y, pese a que el griego era el idioma franco en el mundo oficial y entre las clases cultas y dirigentes, el copto, el arameo, el persa y otros siguieron vivos entre el pueblo y entre los grupos más cerrados - por razones religiosas, sociales, familiares, económicas, u otras- lo cual nos lleva a suponer que las traducciones de textos circularon en ambas direcciones, toda vez que las juventudes nativas de las clases dominantes eran por lo general bilingües, aunque no lo fuesen las de origen griego. En cualquier caso, el hecho de que en los espacios de las Bibliotecas y Gimnasios se propiciara la discusión y la enseñanza permite imaginar hasta dónde podía llegar el intercambio de ideas, saberes, concepciones del mundo, tradiciones etc. de los diferentes pueblos y culturas integrados en el espacio de los reinos helenísticos o en relación con ellos.

El caso mejor conocido ${ }^{3}$ es el del Museo y su aneja Biblioteca de Alejandría. No solo sabemos que su fundación contó con el asesoramiento de los aristotélicos inmediatos a Teofrasto (Estratón de Lampsaco) y que algunos de ellos se instalaron en Alejandría como mentores de la política de helenización de Ptolomeo I, sabemos también que fueron portadores de muchos textos de origen ateniense y que, en casos, la Biblioteca contó con títulos (apócrifos o no) hoy perdidos atribuidos a Aristóteles. La enorme cantidad de libros que llegó a almacenar (más de medio millón) eran una propiedad del Rey, cuya custodia estaba a cargo

${ }^{3}$ Cfr. Fraser, P.M.: Ptolemaic Alexandria (3vls.) Oxford Univ. Press (1972). 
de un funcionario del más alto nivel y confianza real. Los Ptolomeos tuvieron buenos tutores y mostraron siempre interés, a veces notable, por la ciencia y el saber y Ptolomeo IV hizo levantar un templo a Homero y hasta parece escribió una tragedia. Uno de los Seleúcidas escribió algo así como un tratado en verso sobre las mordeduras de serpientes y, como dice R. Lane Fox ${ }^{4}$, "los reyes también competían por el fondo de talento de las antiguas ciudades griegas". La acumulación de libros en las Bibliotecas formaba parte del proyecto helenizador, y las llamadas a los griegos metropolitanos para colaborar en estos proyectos generó una corriente migratoria tan eficaz a la hora de trasladar la cultura griega hacia los nuevos reinos como había sido la antigua política colonial hacia Sicilia, Cirenaica, el Ponto y otros lugares. El préstamo de los rollos que contenían los originales de las tragedias por parte de la Ciudad de Atenas para ser copiados en la Biblioteca fue una de las hazañas de la monarquía ptolemaica, pero su afán bibliófilo comprendía disposiciones como la de registrar los barcos que llegaban a Alejandría y obligarles a prestar los libros que viajasen a bordo, los cuales eran copiados en hojas selladas con la marca "de los barcos" y las copias depositadas en los fondos reales. Cuando Calímaco hizo el gran Catálogo (Pinakés) en tiempos de Ptolomeo II, este ocupó, ya en el s.III ac., nada menos que 120 volúmenes.

La helenización, sin embargo, contó con otras presencias (y hasta competencias) tanto idiomáticas como culturales principalmente en Egipto, en Judea, en Siria o en Persia. En todos los casos parece que con un cierto fondo nacionalista de origen o carácter religioso y vinculadas a un cierto desarrollo de cultura escrita previa. El caso judío es el mejor estudiado, pues disponemos de la crónica judía (los dos primeros libros de los Macabeos) además de las breves noticias dejadas en el entorno helénico. La presencia judía (tras el Edicto de Ciro muchos habían permanecido en Babilonia y otros en otras partes de Asiria de modo voluntario) por todo el mundo helénico tuvo mucho que ver con la posterior generalización del griego como idioma común, pues permitió a los artesanos, comerciantes, y predicadores de todas clases adentrarse en las comunidades de las ciudades sin tener que integrarse en ellas ni en sus costumbres, permitiendo así conservar durante generaciones ciertas formas de identidad cultural o religiosa de origen. Los judíos, aunque muchos helenizados, poseían un corpus religioso-cultural muy definido que canalizó la cohesión de las gentes oriundas de Judea, dentro y fuera de los límites de su lugar de origen. Con todo, los judíos de la Diáspora tanto en su lenguaje como en sus formularios ideográficos se helenizaron mucho más de lo que los textos "canónicos" judíos, controlados por el ultra-nacionalismo

${ }^{4}$ Boardman, J.: op. cit., p.336. 
ortodoxo de los Rabinos de Jerusalén, nos dan a entender. Una amplísima literatura apócrifa ${ }^{5}$ (recordemos que "apócrifo" significa oculto, reservado o secreto) nos muestra a los autores de las diferentes comunidades imbuidos de los modos literarios, filosófico-teológicos del platonismo medio (el ejemplo cumbre es el caso de Filón), éticos o políticos de sus conciudadanos alejandrinos, antioquenos, corintios etc. Y entre los varios textos apócrifos podemos tomar como ejemplos los Libros 3 y 4 de Macabeos, cuya factura, texto y ambiente son enteramente alejandrinos (Ptolomeo IV es el personaje del Libro 3, mientras Simón y Eliazar dos sacerdotes judíos el primero de Jerusalén y el otro de Alejandría lo son del Libro 4) aunque entrañen una moraleja siempre repetida: la Ley (judía) es el camino de la rectitud y la buena razón de nuestra vida y Yahvé es el único Dios, que premia a los buenos y fieles seguidores de la Ley y castiga a quienes no la siguen. Esta idea tan elemental de "palo y zanahoria" admite matizaciones diversas según la filosofía (o teología) que se profese, desde la idea de salvación eterna como máximo premio a la de éxito y felicidad en la vida en la tierra. El maximalismo de la salvación eterna (sotería) tuvo una importancia decisiva en muchos de los movimientos gnósticos y en el cristianismo (especialmente en la versión paulina), mientras que formas menos drásticas de plantear una satisfacción de esta aspiración dieron lugar a innumerables sectas o grupos tanto en Egipto como en otros lugares del mundo helenístico. La literatura patrística y más directamente la apologética dan cuenta de esta proliferación que muchas veces parte de movimientos cristianos y son combatidos como herejías. Así, por el lado ortodoxo figuran los nombres de Justino, Ireneo, Clemente de Alejandría, Orígenes, Tertuliano, Atanasio, Epifanio, Juan Crisóstomo, Basilio, Luciano de Samosata, Agustín... y por el heterodoxo, Basílides, Marción, Valentin, Teodoto, Heracleón, Arrio, ... pero hay otros ejemplos como Apolonio de Tiana o el apostolado de Mani, etc. ${ }^{6}$

Finalmente, para dar cuenta a la vez de la importancia que la Biblioteca de Alejandría daba a la posesión de cuantos libros circulasen por el mundo y del grado de helenización a que llegó la intensa tradición judía, deberíamos recordar aquí lo que los mismos judíos de Alejandría nos han trasmitido sobre un hecho enormemente trascendental en la historia posterior: La Traducción de los Setenta. Recibe este nombre debido a la leyenda sobre su ejecución, transmitida en una célebre Carta de Aristeas a Philocrates, que es un relato de un autor judío alejandrino del siglo I a.c., que tiene como objetivo dignificar la Biblia ante los ojos de

${ }^{5}$ Porter, J. R.: La Biblia Perdida, Edit. BLUME, Barcelona (2010). Es una colección de textos de Apócrifos no incluidos en el Canon.

${ }^{6}$ Cfr. Monserrat Torrents, José: Los Gnósticos. (2vol) Gredos: Madrid (1990). 
sus conciudadanos y adopta la personalidad de un funcionario griego -Aristeas- de la corte de Ptolomeo II que escribe a su hermano -Philocrates-dándole cuenta de cómo llega a la Biblioteca esta nueva obra. Según se nos cuenta, Demetrio de Falero el Bibliotecario de Alejandría informa a Ptolomeo II que la Biblioteca no tiene los libros de los judíos y Ptolomeo pide al Sumo Sacerdote de Jerusalen que le envíe seis representantes de cada tribu lo cual hizo que 72 doctores llegasen a Alejandría y tradujesen el Pentateuco en 72 días y lo hicieron tan perfectamente que, aunque trabajaban independientemente, todos coincidieron en las mismas palabras, por inspiración divina ${ }^{7}$.

Desde el siglo III a.c. los judíos constituían una comunidad numerosa en Alejandría y con la política de Ptolomeo II llegaron a tener relevancia económica y cultural, tanta que es posible afirmar que muchos de ellos se hallaban tan profundamente helenizados que hasta en sus creencias religiosas se helenizaban, no solo en el lenguaje, sino y sobre todo en la interpretación de los textos

en que originariamente se fundaban. De hecho, gran parte de ellos desconocían el idioma hebreo y a casi todos los efectos podrían pasar por griegos de la época. No es muy seguro quién decidió hacer esta traducción, pero es cierto que se hizo por partes y a lo largo de los siglos III-II-I a.c. El Pentateuco fue lo primero y quizá su traducción se debiera a cierta iniciativa patrocinada por el propio Ptplomeo II. Los demás libros del Antiguo Testamento se tradujeron gradualmente a lo largo de los dos siglos siguientes y se fueron ańadiendo a la primera traducción. Los Salmos, los Profetas, Isaías y Jeremías se añadieron a mediados del siglo II (entre 160 y 130 a.c.) y a principios del siglo I a.c. se añadieron La Sabiduría y 3 y 4 de Macabeos que fueron escritos originalmente en griego, y los llamados Libros Deuteronómicos más los Apocalípticos. Esta última colección no fue aceptada en el canon hebreo y así resultaron excluidos Tobías, Judit, 1 y 2 de Macabeos, 1 Esdras, Baruch, Eclesiástico, la Carta de Jeremías, y los añadidos a Esther y a Daniel. El último, ya en el año 100 (d.c.) se añadió el Eclesiastés. Finalmente, en el ańo 90 (d.c.) un grupo de Rabinos reunidos en Jamnia cerró el canon hebreo que incluye menos textos que la versión griega de los setenta. ${ }^{8}$

\footnotetext{
${ }^{7}$ Cfr. Hadas, M.: Aristeas to Philocrates, N.Y. (1951). Repr. Ktav (1973). Contiene el texto griego y su traducción al inglés.

${ }^{8}$ Cfr. Tripolitis, A.: Religions of the Hellenistic-Roman Age. Eerdmans Pub. Comp. Michigan. (2002), p.61 y ss.
} 
No es solo que algunos de los libros del A.T fueran escritos en griego (todos los del Nuevo lo fueron) la traducción misma significó una interpretación pues muchos términos hebreos no tenían un equivalente en griego, lo cual sirvió para introducir términos y conceptos griegos en el ideario judío, y esto, a su vez, llevó a los judíos a una integración conceptual con los valores semánticos de los griegos. El resultado de este proceso fue que la lectura de la Biblia en griego fue un agente helenizador de la mayor importancia y viceversa, para la penetración de las creencias orientales en el mundo griego a través de la traducción de aquellos textos. En poco tiempo la interpretación dejó de ser literal al modo rabínico y pasó a ser alegórica, con lo cual la Biblia adquiere campos referenciales enteros propios de la filosofía griega. Las controversias con los rivales también necesitaron de este bagaje semántico y terminológico pues era el griego el idioma en que se daba la crítica y las réplicas, como nos consta de modo ejemplar en la réplica de Orígenes Contra Celso a la crítica que este hacía a las enseñanzas de los cristianos ${ }^{9}$. Tanto la crítica de Celso (un texto imprescindible, pese a lo fragmentario del mismo) como la respuesta de Orígenes son el mejor ejemplo del proceso de constitución de un lenguaje culto en la terminología utilizada en las controversias teológicas. Este paso resultará fundamental en la historia posterior tanto de la Gnosis $^{10}$ como del nacimiento y formación del corpus teológico inicial del cristianismo. No podemos desconocer que la doctrina de los cristianos (además de los Libros canónicos) se constituyó entre y por los llamados Padres de la Iglesia, casi todos de lengua y formación griegas, además de la multitud de apócrifos declarados heréticos y desaparecidos en buena medida por esa razón.

\section{Religiones y Cultos}

El término sincretismo es el más utilizado y tal vez el que mejor describe el estado de cosas respecto a cualquier aspecto de la época: una mezcla de elementos, ya sean técnicos, ya humanos, religiosos o culturales surgida del contacto entre griegos y no griegos, aunque se haya aplicado con más frecuencia al complejo religioso-filosófico. Los griegos en general constituían la clase dominante

${ }^{9}$ Cfr. Hoffmann R.J.: Celsus On the True Doctrine. A Discourse Against the Christians. Oxford
Univ. Press (1987). Hay una edición D. Ruiz Bueno del Orígenes contra Celso en la BAC,
Madrid (1967), aunque con problemas, para los filólogos, en la traducción de algunos textos.
${ }^{10}$ Cfr. Markschies Christopf: La Gnosis. Herder. Barcelona (2002). Estudio de la Gnosis con-
temporánea del cristianismo de los siglos 1,2 y 3 a la luz de los textos de las Apologías cristia-
nas cuya versión de las doctrinas que combatían no era la más neutral que pudiéramos desear. 
y se establecieron en tan vasto imperio con sus dioses, sus cultos y, en general con su civilización bien establecida. El resto de la población en todo el oriente ya había acumulado una muy larga experiencia integradora de formas y culturas supervenidas con las diferentes invasiones e imperios anteriores. Las corrientes humanas de Oeste a Este y viceversa son muy intensas no solo por la actividad militar, sino por el traslado de pueblos enteros, por la permanencia de la esclavitud en el mercado y por la enorme amplitud del corredor cultural y comercial que se forma a través de todo el mediterráneo cuando Roma entra en contacto con el helenismo desde muy pronto en Sicilia y después en toda Grecia y Asia hasta el Tigris y Egipto. La incorporación de tan extensos territorios era causa más que suficiente para incorporar a su propia cultura el universo helenístico más característico. Pero además el Imperio Parto al Este seguía en relación comercial y cultural con los pueblos de más al Este y no bloqueó por completo la corriente que abrió Alejandro con su conquista inicial. Las influencias iranio-persas (Zoroastro p.e.) llegaron pronto a Occidente y se mantuvieron largo tiempo no solo bajo su forma inicial sino también en el dualismo presente en las sectas religiosas (recordemos a los seguidores de Mani) de inspiración Gnóstica, sobre todo. No pocos estudiosos de los movimientos culturales de este período relacionan al estoicismo y al neo-pitagorismo con influencias orientales del budismo, tras los contactos del ejército de Alejandro.

La helenización de los cultos de cualquier procedencia fue un fenómeno de convergencia tal que al llegar el siglo $1^{\circ}$ de la Era ya se podía hablar de un Culto de los Misterios que abarcaba a todo el mundo helénico y romano, sin que hubiese internas diferencias ya fuese un culto de origen oriental ya procediese de la Grecia clásica. De Grecia procedió el culto de Demeter en Eleusis, con la peculiaridad de ser este su santuario, lugar de su culto, de los festivales en su honor y centro de concurrencia de los griegos de toda la Hélade. Los Misterios principales de su culto sólo se celebraban en Eleusis, una vez al año y existía una especie de "cofradía" o "hermandad" que vinculaba a sus miembros con determinados compromisos, previa una iniciática ceremonia de admisión. Un determinado cuerpo de sacerdotes presididos por un guía espiritual del mayor rango dirigía los ritos y administraba los "bienes" del santuario, ejercía las funciones públicas en nombre de la Diosa y dirigía los ritos de iniciación, purificación y cultos de los adeptos cuyo fin estaba ligado a la felicidad presente y futura bienaventuranza del creyente. El mito aparece descrito ya en la Ilíada (II, 470 y stss.) con la idea de resurrección asociada a los ciclos de la naturaleza, por una parte y con la idea de misterios que deben permanecer en secreto, por otra. La primitiva vinculación de estos ritos a la tarea agrícola de Eleusis y su zona (cultivo del trigo, de la cebada.) 
y su proximidad a Atenas no impidió la expansión de esta devoción a todo el mundo helenizado, incluida Roma, alguno de cuyos Emperadores se iniciaron y pertenecieron a la hermandad de Eleusis, aunque a Nerón ni se le ocurrió pedirlo, pues debía saber que no se aceptaba a persona de mala conducta. Casi nada sabemos de los ritos que conformaban las celebraciones mistéricas, unas en Atenas (Misterios menores) en primavera que culminaban en una procesión hasta Eleusis en cuyas fiestas participaban todos sin secretos ni distinción de condición, y otras en septiembre en Eleusis (Grandes Misterios) durante diez días en los que principalmente intervenían los iniciados y aspirantes a ello y cuyo acto final ocurría en el Telesterion o templo supremo. En ambos casos los ritos incluían abluciones y purificaciones con agua, sacrificios, plegarias y cantos o himnos, comidas y bebidas, entre las cuales estaba el famoso kykeon o bebida sagrada ${ }^{11}$.

Un segundo culto y el más expandido por el mundo helenístico fue el de Dionisio, Baco para los romanos. Debía ser muy antigua la tradición de Dionisio en Grecia pues ya aparece mencionado en la escritura micénica Linear B. Parece que, como Demeter, en su origen está ligado al fenómeno de la vida que nace, muere y vuelve nacer en los cultivos, en los bosques, en la vida animal etc., aunque acabó convertido en el dios del vino y festejado en los eventos de vendimia y demás relacionados con el vino, si bien inicialmente solo las mujeres participaban en ello. Aunque no conocemos cómo eran los ritos es cierto que también tenía iniciados y que en cada lugar había sus particularidades, pero todos eran considerados como el símbolo y anticipo de un destino eterno para cada uno individualmente, destino de eterna vida feliz que la orgía (rito sagrado) anticipaba. En la época clásica pertenecía al culto de Dionisio, entre otros, el universo del Teatro con sus dos grandes géneros (Tragedia- canto del macho cabrío y Comedia- canto de los borrachos). El primero porque el sacrificio del Macho precedía al himno a Dionisio, el segundo por celebrar la llegada del nuevo vino de cada año. El grado de aceptación y el nivel público al que llegaron en el helenismo los festivales dionisíacos alcanzó esplendores comparables con los de Atenas o Corinto. Veamos un ejemplo:

Un día de invierno en Alejandría en 270 ac. Ptolomeo II organizó un gran desfile cuya sección central honraba a Dionisio: Estatuas mecánicas avanzaban sobre enormes carrozas. El vino corría libremente sobre las calles desde enormes tinajas; bebidas frescas se ofrecían a los espectadores: Actores y multitud de

${ }^{11}$ Cfr. Mylonas, George E.: Eleusis and the Eleusinian Mysteries. Princeton University Press. Pinceton (1961) p. 230 y ss. 
mujeres se juntaban a los oficiales disfrazados de sátiros en un Show que incluía escenas de Dionisio borracho regresando de la India, la figura de Alejandro y un enorme falo áureo de 180 pies de largo recubierto de gallardetes y rematado en una gran estrella de oro. La estrella de la mañana abría la marcha, la estrella de la tarde la cerraba. En medio, 2000 bueyes recubiertos de oro, 2400 perros,

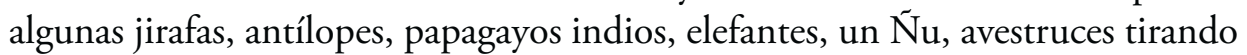
de carros, y un oso blanco (que no era seguramente del ártico). La carroza de "CORINTO" precedía a una parada de mujeres nombradas con los nombres de las ciudades de Jonia y de las islas. Clara alusión a la Liga de Corinto y al compromiso de los Ptolomeos con la libertad de Grecia. Esclavos tiraban de las carretas y los militares desfilaban en centurias. ${ }^{12}$

Aunque no especifica el lugar del que procede esta noticia que el pfr. Lane Fox nos ofrece con tan precisos datos, su mera enumeración de participantes nos sirve aquí para considerar hasta dónde llegaba aquella devoción pública y hasta dónde, por otra parte, muchos de los formatos rituales, tanto religiosos como sociales y políticos, siguen vivos en forma de procesiones, fiestas de patronos y/o benefactores, alardes políticos o conmemoraciones históricas que desde los festejos y los ritos de "Triunfo" estuvieron vigentes en Roma, ya inmediatamente con Sila, los Escipiones, Pompeyo etc. y que aún, si lo consideramos bien, perduran.

Estos festivales se extendieron por todo el mundo helenista y hasta Roma conoció el esplendor de Baco en fiestas. Aunque el Senado (186 ac.) acabó prohibiendo aquellas bacanales que resultaban escandalosas y acaso peligrosas para la salud del pueblo romano, no parece que fuera un Decreto demasiado respetado por las gentes en privado pues el mero testimonio arqueológico de cientos de mosaicos en Villas y casas romanas desenterradas nos serviría de buena prueba.

Pudiéramos añadir aún más datos sobre los Misterios de Cibeles (en Asia primero y en Roma desde el 204 ac), de Isis y de Mithra, (iniciación, purificación, ágapes, consagración, ofrendas y sacrificios rituales, procesiones, santuarios, sacerdocio, etc.) con muchos de los cuales vinieron a coincidir en formato y a veces en contenido muchos ritos cultuales del cristianismo y de las demás religiones mistéricas extendidas por el mundo helenístico, aunque solo el cristianismo llegara a desarrollarse como una sistemática filosofía religiosa, en términos de A. Tripolitis ${ }^{13}$. Y quizá mereciera la pena citar otros aspectos particulares relacionados con las

${ }^{12}$ Lane Fox, R. En Bodman, J., op.cit., p. 333.

${ }^{13}$ Cfr. op. cit., p.104 y ss. 
Revelaciones o Apocalipsis, con la adivinación y la profecía, con la angelología, el monaquismo, las jerarquías internas y la organización de las comunidades, sin olvidarnos tampoco de los ritos que se practicaban en torno a un santoral de dioses menores, ni de los muchos grupos de "hermanos" creados al amparo de doctrinas religiosas de cuño gnóstico y fines soteriológicos, a los que acudían los practicantes en busca de la salvación eterna o incluso de la resurrección, sin la cual también para ellos "vana sería su fe". De todas estas cosas y de otras muchas contamos ahora con instancias presentes en nuestra cultura y en nuestra civilización y de todas ellas podemos hallar sus orígenes o su consolidación en aquella corriente de activa y a veces violenta inter-culturalización.

\section{Saber y civilización}

Una definición aproximada de lo que se entiende por civilización podría resumirse diciendo que es el conjunto de las fórmulas y estrategias que utiliza una sociedad humana para lograr sus objetivos de supervivencia. Simplificando aún más, sus formas de relacionarse con el entorno. Ciertamente estas formas son muy variadas y van desde lo más elemental como el comer o el vestir hasta lo más complejo como las creencias, la organización social, la ciencia o la técnica. La mezcla de culturas que hemos señalado más arriba significó la generalización de una civilización que, por ejemplo, llevó a Egipto nuevas variedades de trigo o el consumo de garbanzos desde zonas muy al norte del mundo helenístico. Los perros de caza, las ovejas de fina lana o los tejidos de algodón y seda se trasladan de un extremo a otro del mundo alejandrino como resultado de las nuevas circunstancias políticas y comerciales. En las costas del Mar Rojo los Ptolomeos fundaron ciudades pobladas con ciudadanos griegos que comerciaban con la India y en Alejandría había maestros brahmines que enseñaban doctrinas budistas. Los reyes seléucidas fundaron decenas de ciudades con el nombre de Antioquía y las dotaron con los elementos propios de una ciudad griega y así sucesivamente. Este juego de intercambios afectó a todos los ámbitos de la vida diaria, hasta el punto de que los artesanos, los médicos, los comerciantes y, en general, los ciudadanos podían pasar de un extremo a otro, de una ciudad a otra o de un reino a otro para ejercer sin interrupción sus saberes de toda índole. Los viajes de Herófilo o de Galeno como médicos nos muestran la facilidad con la cual se movían sabios, artistas o comerciantes en aquel mundo helenizado. 
El Museo o las bibliotecas de Alejandría, de Pérgamo, de Antioquía y muchas otras llegaron a recopilar muchos de los saberes de la época, sobre todo aquellos que estaban contenidos en libros o en instrumentos de alcance científico. Sabemos que existían ábacos para calcular, cilindros para codificar y descodificar mensajes, esferas para representar movimientos de cuerpos celestes, plantillas cuadriculadas para dibujar a escala ya fuesen figuras humanas, animales o construcciones arquitectónicas, etc. Si tratásemos de reconstruir el instrumental de la vida diaria que manejaban desde los artesanos a los cirujanos pasando por los cocineros, los escultores, los navegantes, los agricultores, los mineros, los tejedores, los transportistas, los herreros, los sastres y carpinteros, etc. etc., entraríamos en un universo insospechado de sorpresas, como las propiciadas por las reconstrucciones de la famosa Antikythera, por las exploraciones del túnel de Eupalino en la Isla de Samos o en las hipótesis sobre los métodos de construcción de templos y pirámides o extracción, transporte, izado etc. de los enormes Obeliscos erigidos desde más de veinte siglos antes de la época de Alejandro.

Dejando de lado el interminable debate sobre las relaciones entre ciencia y técnica y también las sutilezas que implica para muchos, podemos afirmar que el mundo alejandrino reunió en sus diferentes centros de cultura (y de poder) una muy amplia panoplia de saberes y técnicas que tenían su expresión (más allá de la filosofía, de las matemáticas y de la astronomía) en las actividades relacionadas con la minería y la metalurgia, con la construcción de edificios y ciudades, con la agricultura, con el armamento y la logística militar y civil, con la medicina y la farmacopea, con la cosmética y todas las artes suntuarias y de lujo, con la náutica en todas sus facetas, ${ }^{14}$ etc.

Sin embargo, pese a la gran complejidad de técnicas y saberes acumulados por el mundo alejandrino, también deberíamos tener presente un hecho, puesto de relieve por casi todos los autores que han estudiado el desarrollo de la técnica y de los saberes asociados a ella, cual es su estancamiento secular a partir de los siglos I-II d.c., y no sólo se estancaron, sino que adquirieron bien poco después un perfil de leyenda, como saberes ritualizados de índole divino-ancestral (pristina sapientia) difíciles de transmitir y casi imposibles de alcanzar, casi asimilados a una revelación perdida. Aún ahora persiste en muchos lugares bajo la forma de esoterismo y "saber antiguo" con la etiqueta de saber secreto. Esta llamada decadencia de la ciencia durante la Edad media no es una cuestión menor, si

\footnotetext{
${ }^{14}$ Cfr. Drachmann, Aage Gerhardt: The Machanical Tecnology of Greek and Roman Antiquity, Copenhague (1963).
} 
queremos comprender el mundo alejandrino como una fase histórica (muy larga, por cierto) de transición entre la antigüedad y la modernidad, fase en la que, a la vez que perdura lo heredado, se origina lo moderno. Llama nuestra atención que una cultura como aquella sea capaz de "inventar" desde las trirremes a la esfera giratoria de Herón, los mecanismos neumáticos de Ctesibio o el tornillo de Arquímedes y no sea capaz de inventar el humilde carretillo, o que pueda construir puertas de apertura automática y no descubra la eficiencia del collar de tiro en el caballo o que fabrique carros de combate arrastrados por dos o cuatro caballos y no sea consciente de las ventajas del estribo para el jinete en la silla de montar, y así sucesivamente. $\mathrm{Y}$, sin embargo, estas ausencias no son el centro del problema, pues la cultura técnica, más allá del carretillo, radica en la Mecánica, la Óptica, la Pneumática, etc., que constituyen el fondo alejandrino de lo que un día será el pórtico de la técnica moderna ${ }^{15}$.

Se ha acudido como intento explicativo a la estructura esclavista del sistema social de producción. Pero resulta claro que un esclavo con un carretillo en las manos es mucho más eficiente y productivo que con una cesta a la espalda a la hora de transportar cualquier mercancía. E igualmente un jinete, militar o no, cabalga más eficientemente con estribos que sin ellos. No menos podemos decir del esclavo molinero que muele en un molino de agua frente al que empuja la muela en un molino de mano. No obstante, el hecho de que las aplicaciones técnicas de lo que se conocía no progresasen hacia la industrialización y se "congelasen" en un estadio inicial y, por lo tanto, no siguiesen progresando hacia nuevos descubrimientos parece más ligado a un problema socio-cultural de seguridad o de riesgo, problema muy complejo cuyos factores principales tienen más que ver con la cultura y la política que con la escasez de bienes o el sistema de producción, Con el Pfr. Lloyd respecto a la agricultura, podemos generalizar la cuestión si consideramos que:

Toda sociedad de mayor o menor entidad debe encargarse de proporcionar el alimento necesario para la supervivencia de sus miembros. En la mayoría de los casos, conseguir dicho objetivo implica el recurso a un extenso conocimiento colectivo de las condiciones del entorno ecológico. Tanto en el caso de la caza, la pesca, el pastoreo o la siembra y el cultivo, una vez que se establece la eficacia de determinados métodos o técnicas, parece haber poco

${ }^{15}$ Cfr. Landels J.G.: (1978 1a) Engineering in the Ancient World. California Univ. Press. (2000). Una muy amplia descripción de casi todos los aspectos del saber técnico en la época greco -romana. 
interés en la innovación, ya que esta implica, probablemente, un altísimo riesgo ...Así que el abandono histórico de métodos y técnicas que ya estaban perfectamente probados y establecidos tuvo que responder quizá a nuevas necesidades......o a la concepción de algún objetivo determinado, como la obtención de riquezas o prestigio social. ${ }^{16}$

"Nuevas necesidades, algún (nuevo) objetivo" significan cambio en el medio en que se vive y adaptación al nuevo medio, con lo que esto tiene de riesgo. Sería imposible desconocer los cambios en el espacio político-social alejandrino ocurridos durante los mil ańos siguientes a la muerte de Alejandro, aunque pudiéramos resumirlos en los avatares del nacimiento, vida y muerte del Imperio Romano (desde el s. II ac.- hasta el s. V dc., en Occidente o s. XV en Oriente). $Y$ si hubo cambios con nuevas necesidades y nuevos objetivos hay que suponer que hubo adaptación a las nuevas necesidades y a los nuevos objetivos. Y quizá el "estancamiento" post-alejandrino tenga mucho que ver con la adaptación a esas nuevas necesidades y nuevo objetivo. Esto nos llevaría a preguntarnos por los términos en que se presentan las nuevas necesidades y los nuevos objetivos para las sociedades post-alejandrinas ${ }^{17}$. No tenían estos mucho que ver, desde luego, con un crecimiento desbocado de las poblaciones ni con el aumento de necesidades materiales de espacio y territorio. Tampoco con escasez de recursos primarios para la subsistencia de las poblaciones, ello pese a las innumerables invasiones y devastaciones de un lado y de otro. No es irrelevante que todo esto ciertamente generase un alto grado de inseguridad y de temor entre las gentes indefensas, pero, pese a todo ello y quizá por ello, sus necesidades procedían de y/o se expresaban en otro orden de cosas. El culto de los misterios sirvió de pórtico para una nueva interpretación del horizonte humano. Los adeptos a estos cultos creían que su salvación (su vida feliz-vita beata) ${ }^{18}$ estaba en otra vida $o$ en otro mundo. Las interpretaciones apocalípticas de los eventos históricos o puramente naturales que introducen el protagonismo de un Poder Superior en el

\footnotetext{
${ }^{16}$ Lloyd, Sir Geoffrey: Las Aspiraciones de la Curiosidad. Siglo XXI. Madrid (2008) -Trad. De Paula Olmos (pp.100-102).

17 También esto nos llevaría a mantener que los humanos, como cualquier otra especie del planeta, viven a "salto de mata", es decir que resuelven la situación que se les presenta con los elementos que tienen a mano y progresan en esa solución encontrada hasta donde les permite la nueva situación lograda. Esta perspectiva permite, de paso, explicar cómo y por qué construyeron grandes monumentos antes que grandes sistemas teóricos al igual que construyeron los lenguajes antes que grandes poemas, etc.

${ }^{18}$ De vita Beata. Es el título de un diálogo de Séneca, pero ahora nos permitimos generalizar a sus expensas para caracterizar una especie de ideario surgido de las diferentes corrientes que se cruzaron en el período alejandrino.
} 
acontecer histórico, por una parte, y el dualismo antropológico de carne-espiritu que introduce el pesimismo natural en el hombre-caido, por otra, se extendieron por el medio cultural post-alejandrino, hasta que se generalizó la necesidad y el objetivo de la salvación, con lo cual acabó instalándose el modelo de la Ciudad de Dios amurallada por el temor del próximo final milenarista.

Si la anticipación (en tanto que simulación del entorno futuro, inmediato o más lejano) es una condición fundamental de la conducta adaptativa humana, no resultaba nada desdeñable para la sociedad post-alejandrina el valor profético de los pretendidos mensajes-revelaciones procedentes de los poderes de un ultramundo que se manifestaba por todas partes. El Hades o el Infierno, el Olimpo o el Paraíso eran familiares a todos y llegaron a ser incluidos universalmente en el imaginario culto tanto como en el popular, independientemente de las creencias concretas propuestas por las diferentes religiones. Oráculos y adivinos, profetas e intérpretes de sueños, predicadores como Apolonio de Tiana o fundadores y maestros de Escuelas como Zenón de Citio, Panecio de Rodas, Posidonio de Apamea, Andrónico de Rodas u Orígenes, escritores como Plutarco, Apuleyo, Cicerón, Lucrecio Caro, Séneca o Tertuliano y un interminable etc., nos servirían como apoyo a la imagen esbozada del predominio adquirido por la idea de vita beata de las escuelas de inspiración socrática y platónica frente a la idea de vita heroica de los tiempos en que primaba la paideia homérica.

Una cuestión que podría llevarnos muy lejos es la que podríamos plantear sobre las causas de la aparición y de la importancia socio-cultural que alcanzaron las instancias místico-religiosas en el mundo alejandrino ${ }^{19}$. Las escuelas no eran instituciones del estado y, salvo en Atenas o en la Biblioteca de Alejandría, no tenían apoyos públicos de los que tengamos noticias. Hasta Marco Aurelio con su patrocinio de las escuelas atenienses, ningún rey o emperador entró en el juego de la enseñanza. En cambio, proliferan las escuelas confesionales, catequéticas o equivalentes (Alejandría, Cesarea, Antioquía, Roma, etc,). Esto excluye a la acción del poder del conjunto de causas directas (al menos hasta la época de Constantino) de la aparición primero y de la generalización después de los movimientos ascético-religiosos o místicos (a veces) que proliferaron desde, al menos, principios del siglo III a.c., por las principales regiones del mundo alejandrino.

\footnotetext{
${ }^{19}$ Por tratarse de una respuesta socio-cultural no es este el lugar para entrar en el debate sobre la idea de "virus de la mente" que Dawkins atribuye al sentimiento religioso (Dawkins: "Viruses of the Mind" en Dennett and his Critics. Edt.de B. Dahlbom Blackwell- Oxford 1993 p.13 y ss.
} 
Equivale esto a preguntarnos por el tipo de necesidades que tenían los hombres del mundo alejandrino y también por el objetivo que perseguían y, por supuesto, por el tipo de respuesta que eligieron para satisfacer a unas y alcanzar el otro. De hecho, tanto el cristianismo como el islamismo acabaron imponiendo sus pautas culturales mayoritarias en todos los ámbitos del mundo helenístico. Y no es ninguno de ellos ajeno a los ideales nacidos en esos siglos que consideramos post-alejandrinos. El hecho es que en ambos casos se produjo la aparición de estados con fórmulas teocráticas divinamente vinculadas a la salvación eterna de los miembros de esas sociedades medio civiles-medio religiosas. Y no resulta exagerado decir que en muchos casos este formulismo aún pervive e impregna partes muy amplias de nuestra sociedad.

No sería, pues, justo desconocer la enorme masa de conocimientos y técnicas presentes en el universo alejandrino y menos aún desconocer la eficacia de su aplicación en los campos de actividad en que lo juzgaron pertinente para su supervivencia tanto en los problemas de construcción material como cultural. Pero tampoco es irrelevante recordar aquí que las necesidades y objetivos de una sociedad humana dependen de entornos siempre inestables que los propios humanos modifican constantemente. Por consiguiente, resultará inevitable responder a esas modificaciones con variaciones en los sistemas de respuesta disponibles, lo que dará lugar a aparentes discontinuidades, apariencia de la que los historiadores nos informan mediante los convencionales (pero arbitrarios) cambios de época. La continuidad de la historia humana, sin embargo, no resulta disuelta en la nada por la gracia de un punto y aparte. La Historia de la vida humana no se interrumpe tan fácilmente como suele aparecer, a veces, en las cronologías saltacionistas que frecuentemente nos presenta la historia Académica. 


\section{Bibliografía}

Boardman J.; Griffin J.; Murray, O. (eds.) (1989). "Greek Historians”, en The Oxford History of Greece and the Hellenistic World. Oxford

Fraser, P.M. (1972). Ptolemaic Alexandria (3vols.) Oxford Univ. Press.

Porter, J.R. (2010). La Biblia Perdida, Barcelona: BLUME.

Monserrat Torrents, J. (i 920). Los Gnósticos. (2vol) Gredos Madrid1990.

Hadas, M. (1951). Aristeas to Philocrates, N.Y. 1951. repr. Ktav.

Tripolitis, A. (2002). Religions of the Hellenistic-Roman Age. Eerdmans Pub. Comp.Michigan.

Mylonas, G. E. (1961). Eleusis and the Eleusinian Mysteries. Princeton University Press. XXI.

Lloyd, Sir Geoffrey (2008): Las Aspiraciones de la Curiosidad. Madrid: Siglo

Dawkins, R. (I 993). "Viruses of the Mind", en Dennett and his Critics. Ed.de B. Dahlbom, Oxford: Blackwell.

Drachmann, A, G. (1963). The Machanical Tecnology of Greek and Roman Antiquity, Copenhague.

Landels J.G.: (1978 1a) Engineering in the Ancient World. California U. Press. (2000).

Recibido: 21/03/2013

Aceptado: 10/9/2016

Este trabajo se encuentra bajo una licencia de Creative Commons ReconocimientoNoComercial-SinObraDerivada 4.0 Internacional 
